\title{
Selective Functionalization of Independently Addressed Microelectrodes by Electrochemical Activation and Deactivation of a Coupling Catalyst
}

\author{
Neal K. Devaraj, Peter H. Dinolfo, Christopher E. D. Chidsey, ${ }^{\star}$ and James P. Collman* \\ Department of Chemistry, Stanford University, Stanford, California 94305-5080
}

Received December 9, 2005; E-mail: jpc@stanford.edu; chidsey@stanford.edu

Recently, we have employed copper(I)-catalyzed 1,2,3-triazole formation (a Sharpless "click" reaction) as a method for covalently modifying surfaces. ${ }^{1-5}$ 1,2,3-Triazole formation between terminal acetylenes and organic azides is efficiently catalyzed by copper(I) complexes, while the oxidized copper(II) complexes are inactive. ${ }^{5}$ Here we report control of this reaction at the surface of an electrode by electrochemically activating or deactivating the catalyst by switching its redox state. The reaction proceeds on the time scale of minutes using submicromolar concentration of reactants and catalyst, requires mild potentials for catalyst activation and deactivation, and works in aqueous and mixed aqueous-organic solvents. By appropriately biasing adjacent electrodes, we have selectively modified one of two chemically identical $10-\mu$ m-wide band electrodes separated by $10 \mu \mathrm{m}$ in an interdigitated array (IDA) (shown in Scheme 1). The ability to independently functionalize each electrode in an array will allow electrically programmed functionality in sensor and actuator arrays, as well as other multielectrode devices.

Initial experiments focused on electrochemically generating the active copper(I) catalyst on macroscopic planar electrodes. Mixed azide-terminated self-assembled monolayers (SAMs) were formed by soaking gold-coated silicon wafers in thiol solutions as previously described (see Supporting Information for experimental details). ${ }^{2}$ The electrode was contacted with a solution of $0.1 \mathrm{M}$ $\mathrm{KPF}_{6}, 0.5 \mu \mathrm{M}$ copper(II) bis(bathophenanthroline)disulfonic acid, ${ }^{6}$ and $0.5 \mu \mathrm{M}$ ethynylferrocene. These low concentrations allow electrochemical detection of the resultant surface-bound ferrocene against the minute electrochemical signals due to the solution species. The gold electrode was biased at $-300 \mathrm{mV}$ versus a $\mathrm{Ag} /$ $\mathrm{AgCl} /$ saturated $\mathrm{NaCl}$ reference electrode. This potential is roughly $300 \mathrm{mV}$ negative of the $\mathrm{Cu}(\mathrm{II} / \mathrm{I})$ standard potential of the catalyst, ensuring that $\mathrm{Cu}(\mathrm{I})$ is formed at the electrode surface. Figure 1a shows real-time monitoring of the reaction progress by cyclic voltammetry $(\mathrm{CV})$. Over a period of minutes, a clear surfaceimmobilized ferrocene signal grows in at $+300 \mathrm{mV}$ versus $\mathrm{Ag} /$ $\mathrm{AgCl} /$ saturated $\mathrm{NaCl}^{7}$ As demonstrated in the Supporting Information, $\mathrm{CVs}$ taken with only the catalyst present show that the kinetically slow couple observed in Figure 1a at $0 \mathrm{mV}$ versus $\mathrm{Ag} /$ $\mathrm{AgCl} /$ saturated $\mathrm{NaCl}$ is due to a surface-localized copper species.

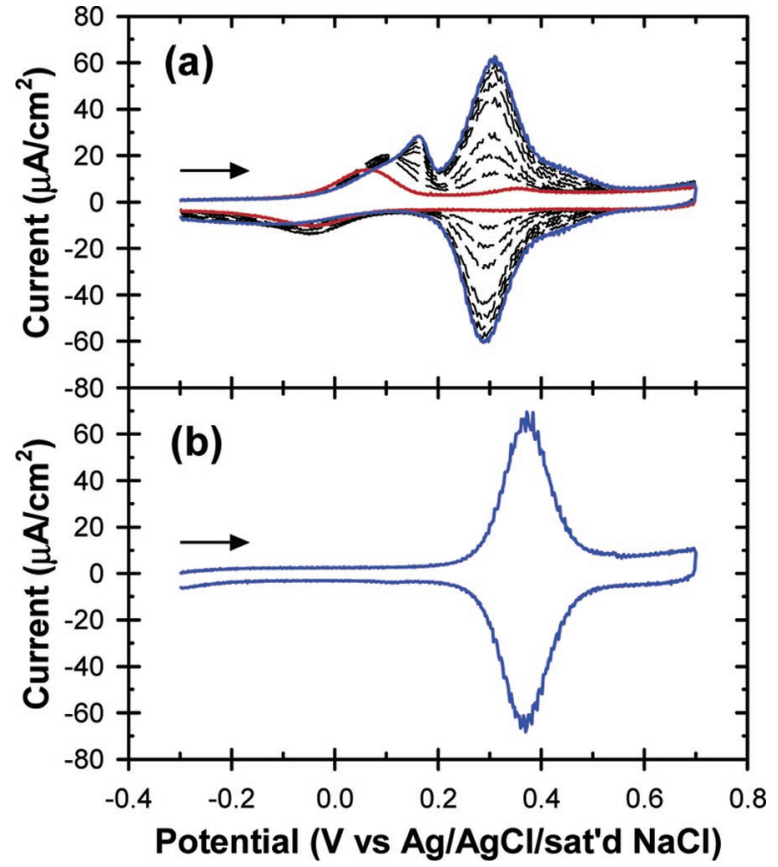

Figure 1. $\mathrm{CVs}$ (1 V/s scan rate) of a mixed SAM on gold formed from a $0.1 \mathrm{mM}$ ethanolic solution of $\mathrm{N}_{3}\left(\mathrm{CH}_{2}\right)_{16} \mathrm{SH}$ and $\mathrm{CH}_{3}\left(\mathrm{CH}_{2}\right)_{11} \mathrm{SH}$, where the mole fraction of azide to diluent was 0.2 . Arrows indicate start of the scan. (a) Scans taken every $2 \mathrm{~min}$ during the $18 \mathrm{~min}$ functionalization of the monolayer by ethynylferrocene. Electrolyte $0.1 \mathrm{M} \mathrm{KPF}_{6}, 0.5 \mu \mathrm{M}$ copper(II) bis(bathophenanthroline)disulfonic acid, and $0.5 \mu \mathrm{M}$ ethynylferrocene; initial scan shown as red line, intermediate scans as dashed black lines, and final as blue line. (b) Scan taken after the monolayer was functionalized and rinsed. Electrolyte $1 \mathrm{M} \mathrm{HClO}_{4}$.

When the ferrocene signal ceased to grow, the electrode was disconnected and cleaned with water, ethanol, chloroform, ethanol, and then water to ensure that any noncovalently bound copper and ferrocene was removed. The electrode was then contacted with 1 $\mathrm{M} \mathrm{HClO}_{4}$. A CV (Figure 1b) indicated that the ethynylferrocene had coupled to the surface. Control reactions were performed in an identical manner but with the cell left at the open-circuit potential or with a monolayer that contained no azide-terminated thiols. In

Scheme 1

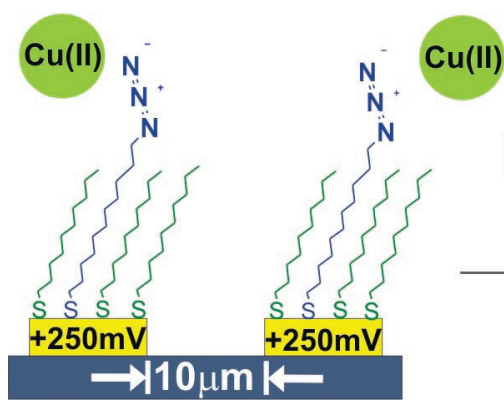

1794 I J. AM. CHEM. SOC. 2006, 128, 1794-1795

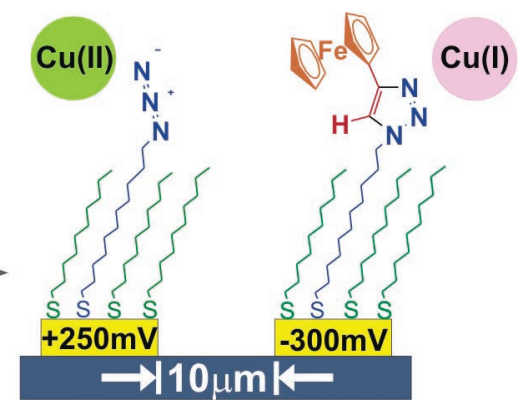

10.1021/ja058380h CCC: $\$ 33.50$ @ 2006 American Chemical Society 


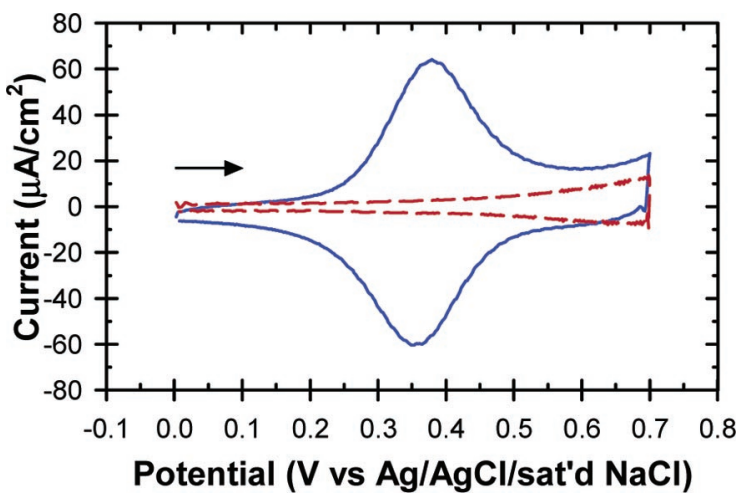

Figure 2. CVs of mixed SAMs formed on gold IDA microelectrodes from a $0.1 \mathrm{mM}$ ethanolic solution of $\mathrm{N}_{3}\left(\mathrm{CH}_{2}\right)_{11} \mathrm{SH}$ and $\mathrm{CH}_{3}\left(\mathrm{CH}_{2}\right)_{10} \mathrm{SH}$, where the mole fraction of azide to diluent was approximately 0.2. After functionalization and thorough washing, CVs were recorded at $1 \mathrm{~V} / \mathrm{s}$ in 1 $\mathrm{M} \mathrm{HClO}_{4}$. Electrode 1 is shown as a blue line and Electrode 2 as a dashed red line. Arrows indicate start of the scan. During the 30 minute functionalization, Electrode 1 was held at $-300 \mathrm{mV}$ and Electrode 2 held at $+250 \mathrm{mV}$ versus $\mathrm{Ag} / \mathrm{AgCl} /$ saturated $\mathrm{NaCl}$ in $0.1 \mathrm{M} \mathrm{KPF}_{6}$ electrolyte with $1 \mu \mathrm{M}$ copper(II) bis(bathophenanthroline)disulfonic acid and $5 \mu \mathrm{M}$ of ethynylferrocene.

either case, no ferrocene surface couple was detected. The general technique showed an excellent tolerance to reaction conditions, working well in mixed solvents (such as water and dimethylsulfoxide), with mixed monolayers containing either aromatic or alkyl azides and hydrophilic or hydrophobic diluent thiols, as well as with other copper complexes, such as a water-soluble $\mathrm{Cu}$ (II) tris(triazolylmethyl)amine. ${ }^{8,9}$

To demonstrate that this technique can be applied to the selective functionalization of independently addressable microelectrodes, we performed the reaction on a commercially available pair of gold interdigitated array (IDA) band electrodes (Abtech Scientific). The IDA was composed of two electrodes each consisting of $50 \mathrm{Au}$ fingers $5 \mathrm{~mm}$ long by $10 \mu \mathrm{m}$ wide, with an interelectrode spacing of $10 \mu \mathrm{m}$. Identical mixed azide-terminated self-assembled monolayers were formed on both gold electrodes. The IDA was contacted with a solution of $0.1 \mathrm{M} \mathrm{KPF}_{6}, 1 \mu \mathrm{M}$ copper(II) bis(bathophenanthroline)disulfonic acid, and $5 \mu \mathrm{M}$ ethynylferrocene. The electrode we wished to functionalize (Electrode 1) was held at $-300 \mathrm{mV}$, whereas the electrode we did not want to functionalize (Electrode 2) was held at $+250 \mathrm{mV}$ versus $\mathrm{Ag} / \mathrm{AgCl} /$ saturated $\mathrm{NaCl}$ using a bipotentiostat (Pine Instruments). After $30 \mathrm{~min}$, both electrodes were disconnected, rinsed, and contacted with $1 \mathrm{M} \mathrm{HClO}_{4}$ electrolyte. As Figure 2 depicts, Electrode 1 was found to be functionalized with ferrocene, whereas Electrode 2 was not. In a separate experiment, the two electrodes were each functionalized in succession by first holding Electrode 1 at $-300 \mathrm{mV}$ and Electrode 2 at $+250 \mathrm{mV}$ for $30 \mathrm{~min}$ and then switching the voltages at which the electrodes were held and again holding for $30 \mathrm{~min}$. The resulting CVs taken with $1 \mathrm{M} \mathrm{HClO}_{4}$ electrolyte showed that the two electrodes were functionalized with ferrocene, and the coverages were nearly identical (see Supporting Information).

When Electrode 2 was left at open-circuit during functionalization of Electrode 1, Electrode 2 was found to be partially functionalized with ferrocene (typically less than $10 \%$ that of Electrode 1), indicating that the activated catalyst was able to diffuse from Electrode 1 to Electrode 2. However, if all the activated catalyst were soluble, then, given the separation of $10 \mu \mathrm{m}$ between the two electrodes and the time scale of reaction, Electrode 2 would have been completely functionalized. That this is not the case suggests that most of the activated catalyst is localized on the surface of
Electrode 1. This is consistent with the electrochemical detection of a surface-localized copper(I) species, as seen in Figure 1a and discussed further in the Supporting Information. This would explain why Electrode 2 was not fully functionalized when left at opencircuit, as well as why the reaction works so quickly at such low concentrations of the copper(II) species.

A popular strategy to selectively modify multielectrode arrays is to electrochemically activate a surface-immobilized reactant. ${ }^{10-16}$ However, there are several advantages in modulating catalyst activity rather than reactant activity. ${ }^{17,18}$ The latter is necessarily stoichiometric, whereas a single catalyst can amplify the response due to a single electron. Another benefit is increased flexibility in what can be immobilized on the surface; the surface reactant need not be electroactive.

In summary, we have demonstrated selective functionalization of independently addressable electrodes by electrochemical activation and deactivation of a coupling catalyst. 1,2,3-Triazole formation at a mixed azide-terminated SAM can be controlled by electrically addressing an electrode to generate the active copper(I) catalyst. This technique can be used to discriminate between chemically identical but independently addressable electrodes, and we have demonstrated this by selectively functionalizing a $10 \mu \mathrm{m}$ spaced IDA of microelectrodes. The ability to switch on or off the reaction by electrical addressing together with the chemoselectivity of this reaction makes $\mathrm{Cu}(\mathrm{I})$-catalyzed triazole formation an ideal method for the chemical modification of multielectrode arrays.

Acknowledgment. We thank Wataru Ebina for preparing the aryl azide-terminated thiol. N.K.D. acknowledges a Stanford Graduate Fellowship and helpful discussions with Richard A. Decreau, Charles C. L. McCrory, and Joshua B. Ratchford. This material is based upon work supported by the NIH under Grant GM-69568-01A1.

Supporting Information Available: Detailed experimental procedures and additional voltammetric data. This material is available free of charge via the Internet at http://pubs.acs.org.

\section{References}

(1) Kolb, H. C.; Finn, M. G.; Sharpless, K. B. Angew. Chem., Int. Ed. 2001, 40 (11), 2004-2021

(2) Collman, J. P.; Devaraj, N. K.; Chidsey, C. E. D. Langmuir 2004, 20 (4), $1051-1053$

(3) Devaraj, N. K.; Miller, G. P.; Ebina, W.; Kakaradov, B.; Collman, J. P.; Kool, E. T.; Chidsey, C. E. D. J. Am. Chem. Soc. 2005, 127 (24), 86008601 .

(4) Lee, J. K.; Chi, Y. S.; Choi, I. S. Langmuir 2004, 20 (10), 3844-3847.

(5) Rostovtsev, V. V.; Green, L. G.; Fokin, V. V.; Sharpless, K. B. Angew. Chem., Int. Ed. 2002, 41 (14), 2596-2599.

(6) Lewis, W. G.; Magallon, F. G.; Fokin, V. V.; Finn, M. G. J. Am. Chem Soc. 2004, $126(30), 9152-9153$.

(7) The initial CV also shows some ferrocene that is either nonspecifically bound or in solution.

(8) Chan, T. R.; Hilgraf, R.; Sharpless, K. B.; Fokin, V. V. Org. Lett. 2004, 6 (17), 2853-2855.

(9) Zhou, Z; Fahmi, C. J. J. Am. Chem. Soc. 2004, 126 (29), 8862-8863.

(10) Bunimovich, Y. L.; Ge, G. L.; Beverly, K. C.; Ries, R. S.; Hood, L.; Heath, J. R. Langmuir 2004, 20 (24), 10630-10638.

(11) Curreli, M.; Li, C.; Sun, Y. H.; Lei, B.; Gundersen, M. A.; Thompson, M. E.; Zhou, C. W. J. Am. Chem. Soc. 2005, 127 (19), 6922-6923.

(12) Hodneland, C. D.; Mrksich, M. Langmuir 1997, 13 (23), 6001-6003.

(13) Kim, K.; Jang, M.; Yang, H. S.; Kim, E.; Kim, Y. T.; Kwak, J. Langmuir 2004, 20 (10), 3821-3823

(14) Kim, K.; Yang, H.; Kim, E.; Han, Y. B.; Kim, Y. T.; Kang, S. H.; Kwak, J. Langmuir 2002, 18 (5), 1460-1462.

(15) Yeo, W. S.; Mrksich, M. Adv. Mater. 2004, 16 (15), 1352-1356.

(16) Yousaf, M. N.; Mrksich, M. J. Am. Chem. Soc. 1999, 121 (17), 42864287.

(17) Tesfu, E.; Maurer, K.; Ragsdale, S. R.; Moeller, K. D. J. Am. Chem. Soc. 2004, $126(20), 6212-6213$

(18) Tian, J.; Maurer, K.; Tesfu, E.; Moeller, K. D. J. Am. Chem. Soc. 2005 127 (5), 1392-1393

JA058380H 